\section{Invasive Cutaneous Rhizopus Infections in an Immunocompromised Patient Population Associated with Hospital Laundry Carts}

Mucormycosis is an invasive fungal infection with high morbidity and mortality that most commonly occurs in immunocompromised hosts. ${ }^{1-5}$ Cutaneous mucormycosis is rare and can be acquired through direct contact of the fungi with non-intact skin or mucous membranes. ${ }^{3,4,7-9}$ Outbreaks of mucormycosis associated with contaminated adhesive bandages, ostomy supplies, wooden tongue depressors, and linen have been published. ${ }^{1,6-9}$ This is a report of a cluster of cutaneous mucormycosis with Rhizopus that occurred in 4 immunocompromised inpatients housed primarily in the same intensive care unit (ICU) prior to infection.

In fall 2014, infection (Rhizopus) of the skin and soft tissue was recognized in the axillae of 2 immunocompromised patients. In fall 2015, 2 additional cases (Rhizopus) were identified in the axillae of immunocompromised patients in the same ICU. The underlying diseases of the 4 cases included 3 leukemia patients ( 2 post stem cell transplant) and 1 patient on a high dosage of steroids. Following identification of the initial cases, a retrospective chart review was conducted for each patient to determine risk factors and location(s) of patients prior to infection. These locations were inspected, renovation/construction records were reviewed, and the patient's healthcare providers were interviewed. Sampling of the air and products commonly applied to the axilla (antifungal powder, deodorant, and baby powder) was conducted using standard microbiological methods (Table 1). Upon recognition of 2 additional cases in the same ICU 1 year later, additional chart reviews and healthcare provider interviews were conducted. Environmental sampling was broadened to include linen carts, wicking gauze used occasionally on the axilla, and surfaces in supply rooms (Table 1).

Air and product samples after the initial cases were negative for Rhizopus. After the additional cases, repeat air and linen samples were negative, and environmental sampling showed 1 colony of Rhizopus on a shelf in a clean storage room and 1 colony on the box containing the wicking gauze, but the gauze was negative. The 3 linen carts stored in the clean storage rooms of the ICU were sampled after the additional cases. All 3 carts grew multiple colonies and species of Aspergillus, and 2 linen carts showed multiple colonies of Rhizopus (Table 1).

Infections with Rhizopus in other areas of the hospital had not been detected, so it was uncertain whether the linen carts were the primary source of the contamination or if the containers were somehow being contaminated in this particular
ICU. The decision was made to perform environmental sampling of linen carts in 4 additional ICUs. Carts in 3 of the 4 ICUs also showed Rhizopus sp., as well as multiple colonies and species of Aspergillus (Table 1). Matrix-assisted laser desorption/ionization (MALDI) time of flight (TOF) mass spectroscopy analysis revealed that 3 of the patient infections were due to $R$. oryzae and 1 was due to $R$. microporus. Analysis of the linen cart isolates revealed $R$. oryzae and $R$. microsporus.

A review of our linen protocols revealed that clean linen was delivered from an offsite laundry facility. The clean linen carts, or exchange carts, were assigned to individual patient units and were exchanged daily. At the laundry facility, a clean linen exchange cart was created for each unit, covered, delivered, and stored within the hospital before delivery to the unit. Soiled linen was collected in separate soiled linen carts and sent to the laundry facility. We visited the laundry facility to assess how the linen was processed. The exchange carts were returned to the laundry facility, weighed to determine how much linen was used, and then returned to the stocking area with unused linen, to be refilled. The carts and cart covers were being cleaned only if visibly soiled. The linen vendor reported that this was a typical procedure and acceptable under the Hospital Linen Accreditation Council (HLAC), by which this facility was accredited. HLAC standards were reviewed and stated: "Carts, containers, reusable cart covers, and liners used for clean textiles shall be properly cleaned and disinfected after the cart is emptied and upon return to the facility." ${ }^{10}$ The standard also stated: "Carts shall be cleaned and disinfected by steam cleaning, cleaning with a detergent and water or by using an EPA-registered hospital grade detergent/ disinfectant." 10

Interventions were immediately implemented to have all clean linen exchange carts emptied and cleaned thoroughly with an EPA-registered disinfectant detergent. This was followed by conversations with the linen facilities administration to implement a process that would ensure all linen exchange carts and covers would be cleaned per HLAC recommendations on a routine basis (eg, daily, weekly). Currently, periodic environmental cultures are being performed on linen exchange carts and covers to assess for compliance and resolution of contamination. To date, there has been a substantial decrease in the recovery of the opportunistic fungi Rhizopus and Aspergillus from the laundry carts (8.1 opportunistic fungi/Rodac vs 1.2 opportunistic fungi/Rodac before and after intervention, $P=.0051$; Table 1 ). In addition, there have been no additional patient infections with Rhizopus.

Linen has been implicated previously in outbreaks of mucormycosis. ${ }^{1,9}$ We believe that this outbreak was caused by transmission of Rhizopus from contaminated linen carts via contaminated linen to patients. The investigation 
TABLE 1. Recovery of Opportunistic Fungi From the Hospital Environment ${ }^{\mathrm{a}}$

\begin{tabular}{|c|c|c|}
\hline \multirow[b]{2}{*}{ Site } & \multicolumn{2}{|c|}{ Results (No. Positive/Total No. Cultures) } \\
\hline & Pre-intervention & Post-intervention \\
\hline Toiletries (antiperspirant, powder) & $0 / 3$ & $\ldots$ \\
\hline Patient room (vol. air sampling) & $0 / 1$ & $\ldots$ \\
\hline Hallway outside patient room (vol. air sampling) & $0 / 1$ & $\ldots$ \\
\hline \multirow[t]{2}{*}{ Clean Utility Room (vol. air sampling) } & $2 / 2$ & $\ldots$ \\
\hline & 4 Aspergillus sp. & \\
\hline Clean Utility Room \#2 (Rodac Plate) & $0 / 1$ & $\ldots$ \\
\hline Warmer in utility room & $0 / 2$ & $\ldots$ \\
\hline Vent in utility room & $0 / 2$ & $\ldots$ \\
\hline Counter in utility room & $0 / 2$ & $\ldots$ \\
\hline \multirow[t]{2}{*}{ Shelf in utility room } & $1 / 1$ & $\ldots$ \\
\hline & 1 Rhizopus & \\
\hline \multirow[t]{3}{*}{ Wicking gauze } & $1 / 2$ & $\ldots$ \\
\hline & 1 Rhizopus & \\
\hline & 1 Aspergillus & \\
\hline Linen & $0 / 5$ & $\ldots$ \\
\hline \multirow[t]{2}{*}{ Top of blue linen cart cover (outside) } & $9 / 9$ & $2 / 7$ \\
\hline & $\begin{array}{c}87 \text { Aspergillus sp. } \\
8 \text { Rhizopus sp. }\end{array}$ & 3 Aspergillus sp. \\
\hline \multirow[t]{2}{*}{ Side of blue linen cart cover (outside) } & $7 / 9$ & $1 / 7$ \\
\hline & $\begin{array}{l}17 \text { Aspergillus sp. } \\
5 \text { Rhizopus sp. }\end{array}$ & 1 Rhizopus sp. \\
\hline \multirow[t]{3}{*}{ Inside of linen cart (rear and floor) } & $9 / 9$ & $5 / 7$ \\
\hline & 101 Aspergillus sp. & 21 Aspergillus sp. \\
\hline & 3 Rhizopus sp. & 1 Rhizopus sp. \\
\hline Water & $0 / 6$ & $\ldots$ \\
\hline
\end{tabular}

\footnotetext{
${ }^{a}$ All microbiologic cultures were conducted using a Rodac plate with the exception of water $(2 \mathrm{~L}, 0.2-\mu$ filter $)$, toiletries (direct plated), ventilation duct (direct plated from swab), and volumetric air sampling of $1,000 \mathrm{~L} \mathrm{or} 1 \mathrm{~m}^{3}$ of air (Bioscience International, Rockville, MD). Air sampling, water, ventilation duct and linen carts were done utilizing Sabourauds dextrose media. Other sampling was conducted with Dey-Engley neutralizing agar.
}

demonstrated the potential for disease transmission from inadequate handling of linen and emphasizes the importance of knowing how individual facilities process and handle linen. Routine assessment of a facility's linen handling processes and knowledge of current industry standards for hospital linen processing is imperative. This investigation also highlights the important role of the infection preventionist in recognizing a potential outbreak by performing hospitalwide surveillance for all types of healthcare-associated infections.

\section{ACKNOWLEDGMENTS}

Financial support: No financial support was provided relevant to this article.

Potential conflicts of interest: Drs. Rutala and Weber are consultants for Clorox. Dr. Rutala has received honoraria from 3M. All other authors report no conflicts of interest relevant to this article.

Lisa J. Teal, BSN; ${ }^{1}$ Katherine M. Schultz, MPH; ${ }^{1}$ David J. Weber, MD, MPH; ${ }^{1,2}$ Maria F. Gergen, MT(ASCP); ${ }^{1}$ Melissa B. Miller, PhD; ${ }^{3}$

\section{Lauren M. DiBiase, MS; ${ }^{1}$ Emily E. Sickbert-Bennett, PhD; ${ }^{1,2}$ William A. Rutala, MPH, $\mathrm{PhD}^{1,2}$}

Affiliations: 1. Hospital Epidemiology, University of North Carolina Health Care, Chapel Hill, NC, 27514; 2. Division of Infectious Diseases, UNC School of Medicine, Chapel Hill, NC 27599-7030; 3. Microbiology, University of North Carolina Health Care, Chapel Hill, NC 27514.

Address correspondence to Lisa Teal, RN, BSN, CIC, Infection Preventionist University of North Carolina Hospital, Room 1001 West Wing, UNC Health Care, Chapel Hill, NC 27514 (Lisa.Teal@unchealth.unc.edu).

Received April 14, 2016; accepted June 8, 2016; electronically published July 26, 2016

Infect Control Hosp Epidemiol 2016;37:1251-1253

DOI: $10.1017 /$ ice.2016.157

\section{REFERENCES}

1. Duffy J, Harris J, Gade L, et al. Mucormycosis outbreak associated with hospital linens. Pediatr Infect Dis J 2014;33: 472-476.

2. Llata E, Blossom DB, Khoury HJ, et al. A cluster of mucormycosis infections in hematology patients: challenges in investigation and 
control of invasive mold infections in high-risk patient populations. Diagn Microbiol Infect Dis 2011;71:72-80.

3. Garner D, Machin K. Investigation and management of an outbreak of mucormycosis in a paediatric oncology unit. J Hosp Infect 2008;70:53-59.

4. Mays SR, Bogle MA, Bodey GP. Cutaneous fungal infections in the oncology patient: recognition and management. Am J Clin Dermatol 2006;7:31-43.

5. Kanamori H, Rutala WA, Sickbert-Bennett EE, Weber DJ. Review of fungal outbreaks and infection prevention in healthcare settings during construction and renovation. Clin Infect Dis 2015;61:433-444.

6. Li H, Hwang SK, Zhou C, Du J, Zhang J. Gangrenous cutaneous mucormycosis caused by Rhizopus oryzae: a case report and review of primary cutaneous mucormycosis in China over Past 20 years. Mycopathologia 2013;176:123-128.

7. Rammaert B, Lanternier F, Zahar JR, et al. Healthcare-associated mucormycosis. Clin Infect Dis 2012;54:S44-S54.

8. Lalayanni C, Baliakas P, Xochelli A, et al. Outbreak of cutaneous zygomycosis associated with the use of adhesive tape in haematology patients. J Hosp Infect 2012;81:213-215.

9. Cheng VC, Chen JH, Wong SC, et al. Hospital outbreak of pulmonary and cutaneous zygomycosis due to contaminated linen items from substandard laundry. Clin Infect Dis 2016; 62:714-721.

10. Accreditation Standards. Healthcare Laundry Accreditation Council website. http://www.hlacnet.org/\#!standards-documents/ c16hh. Published 2011. Accessed November 11, 2015. 